\title{
Depletion of Glutathione during Oxidative Stress and Efficacy of N-Acetyl Cysteine: An Old Drug with New Approaches
}

\section{Manjula Ramen $\mathrm{T}^{*}$}

Sri Ramachandra Medical College and Research Institute, Sri Ramachandra University, Chennai, India

\begin{abstract}
Glutathione, a non-protein thiol is most abundant in cells and glutathione-glutathione disulfide is the major redox pair in animal cells. Its synthesis is from two main enzymes gamma glutamyl cysteinyl synthetase and GSH synthetase. Also cysteine availability as $\mathrm{N}$-acetyl cysteine and $\mathrm{GSH}$ feedback mechanism determines the reduced glutathione status of the cell. Additionally parenteral NAC, cystine, methionine are effective precursors of cysteine for tissue GSH synthesis. Adequate protein in the diet is crucial for tissue GSH synthesis. The role of NAC as an antioxidant, in gene expression, and regulation of cellular events must be emphasized. GSH deficiency contributes to oxidative stress and it progresses in diseased conditions such as HIV, AIDS, cancer, diabetes, also metabolic syndrome. New knowledge of the nutritional regulation of GSH metabolites is critical to improve health and treat these diseases.
\end{abstract}

Keywords: N-Acetyl L Cysteine; Oxidative stress; Antioxidant; Cell regulator

\section{Introduction}

Glutathione is a tripeptide that maintains intracellular levels of reduced glutathione. Its redox action makes it an important biological antioxidant.Gamma-glutamyl-cysteinyl-glycine is synthesized from glutamate, together with cysteine and glycine through the gamma glutamyl cycle. As a key modulator of cell functions, the most abundant non protein thiol (GSH) has important roles in cellular defense against cellular oxidant aggression, redox regulation of protein thiols and maintaining redox homeostasis that is critical for proper functioning of cellular processes including apoptosis. The shift in the cellular GSHGSSG decides the fate of the cell.

Glutamate is a precursor of two gamma-glutamyl compounds of major biochemical importance glutamine and glutathione. Gamma amino butyrate, a neurotransmitter and glutamine are synthesized from glutamate. Glutamine synthetase reaction takes place in a number of mammalian tissues eg, liver, brain, kidney, muscle, intestine [1]. It is the central compound in nitrogen metabolism. It functions in the uptake, storage and formation of ammonia, the homeostatic control of amino acid balance, the synthesis of the purine and pyrimidine moieties of nucleic acids, ATP, and other nucleotides and coenzyme formation and formation of amino sugars.

The synthesis of glutathione involves the uptake and release of amino acids from gamma glutamyl linkage, in a cyclical process termed, the gamma glutamyl cycle (Figure 1). The gamma glutamyl cycle has properties that fulfill the requirements of an amino acid transport system.

The presence of gamma glutamyl cyclotransferase, transpeptidase and gamma glycylsynthetase leads to catalytic events of synthesis and breakdown of glutathione and coupled uptake and release of free amino acids from gamma glutamyl linkages through gamma glutamyl cycle.

The gamma glutamyl cycle may play a role in the transport or secretory functions of many tissues and the ubiquitous occurrence of glutathione reflects its central role in amino acid transport [2].

The transport of amino acid involves a number of steps such as binding of the amino acid to the site on the cell membrane, its carrier mediated translocation, intracellular release of the amino acid from the carrier and reactivation of the carrier in an energy requiring process utilizing glutathione.

Gamma glutamyl transpeptidase key enzyme of GSH metabolism can modify crucial redox sensitive functions as antioxidant/antitoxic balance and cellular proliferation/apoptotic balance with potential implication in tumour progression and drug resistance.

Glutathione is used for detoxication reactions, some of which lead to the formation of mercapturic acids. The initial step in the formation of mercapturic acids involves a reaction of a foreign compound with the sulphydryl group of glutathione within the cell to yield a glutathione adduct catalyzed by glutathione-S- transferases [3].

L-Cysteine, as $\mathrm{N}$-acetyl cysteine (a direct precursor to glutathione synthesis) is a nutritional supplement that replenishes intracellular GSH. It is a safe antidote for glutathione deficiency in a wide range of infections, genetic defects and metabolic disorders including HIV and COPD. GSH serve as a protective agent and detoxify reactive species both enzymatically and non-enzymatically. The aim of this report is three fold. 1) To understand that GSH deficiency is a common cause of oxidative stress in physiological processes including aging and requires antioxidant therapy along with treatment. 2) Besides being an intracellular antioxidant, NAC performs multifunctional roles in the cell as in nutrient metabolism, in cell events, immune response and protein glutathionylation. 3) The most copious antioxidant in the cell and its therapeutic role(Redox Signaling) preventing further cell damage caused by oxidative stress as in aging , atherosclerosis, and an adduct formation with the oxidant as in oxalate load injury makes it the most sought after antioxidant for most cellular mechanisms showing glutathione deficiency.

During last 50 years free radicals have been shown to substantially contribute to the primary cause of the disease in the following sequence.

Disease /toxin-- $\rightarrow$ cell damage/death- $\rightarrow$ increased lipid per oxidation (John M.C. Gutteridge) [4].

*Corresponding author: Manjula Ramen T, Sri Ramachandra Medical College and Research Institute, Sri Ramachandra University, Chennai, India, Tel: 91-4445928500; E-mail: manjuramtk@yahoo.co.in

Received December 22, 2014; Accepted January 23, 2015; Published January 26, 2015

Citation: Manjula Ramen T (2015) Depletion of Glutathione during Oxidative Stress and Efficacy of N-Acetyl Cysteine: An Old Drug with New Approaches. Med chem 5: 037-039. doi:10.4172/2161-0444.1000240

Copyright: (c) 2015 Manjula Ramen T. This is an open-access article distributed under the terms of the Creative Commons Attribution License, which permits unrestricted use, distribution, and reproduction in any medium, provided the original author and source are credited. 


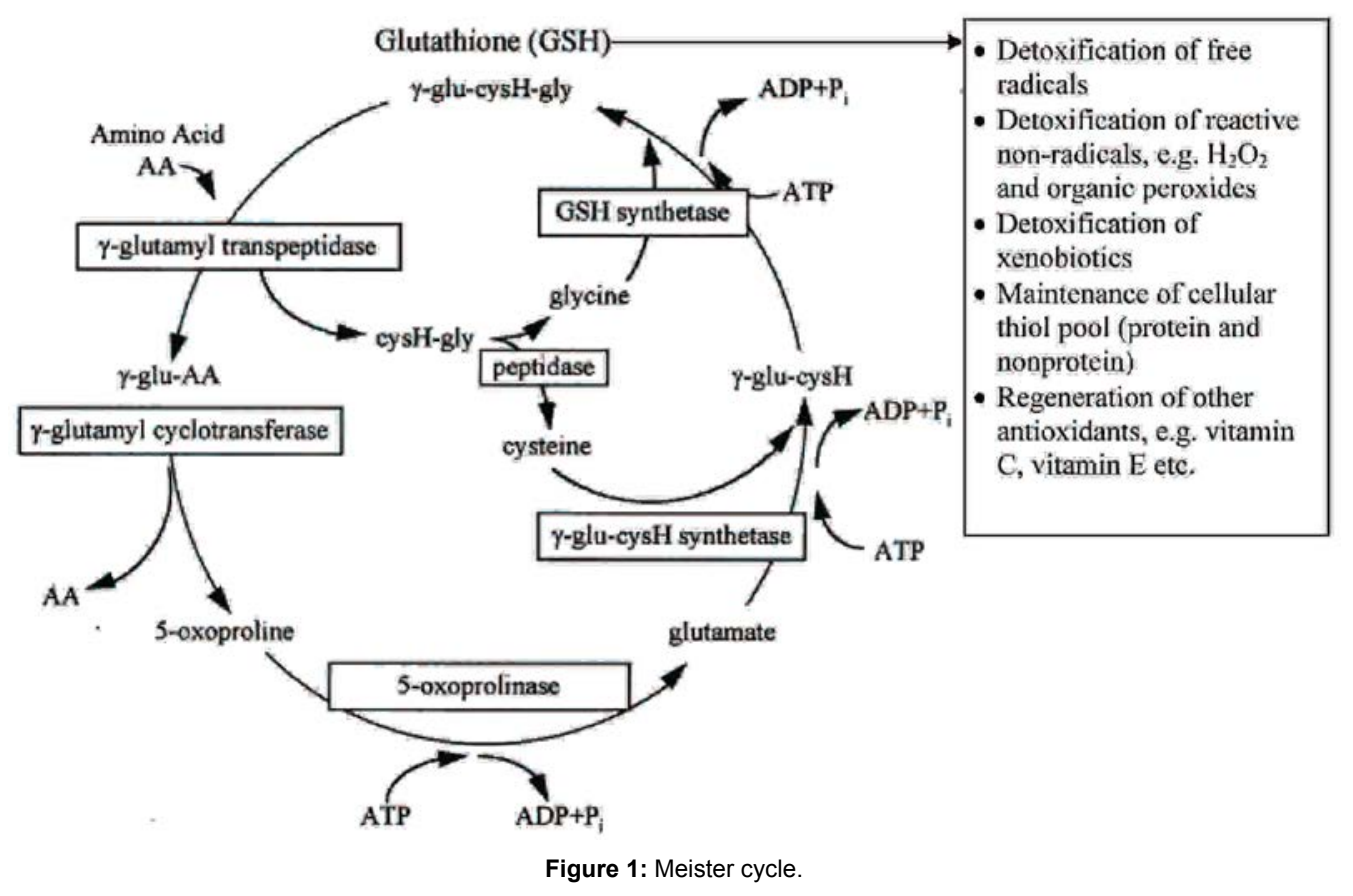

Excess production of free radicals such as superoxide (o2), hydrogen peroxide $\left(\mathrm{H}_{2} \mathrm{O}_{2}\right)$ and hypochlorous acid $(\mathrm{HOCl})$ by activated phagocytes are produced as a consequence of the underlying disease process.

Oxidation-reduction based regulation [5,6] of signal transduction and gene expression is emerging as a fundamental regulatory mechanism in cell biology. Electron flow through side chain functional $\mathrm{CH} 2 \mathrm{SH}$ of conserved cysteinyl residues in proteins account for their redox signaling properties. Because in most intracellular proteins, thiol groups are strongly buffered against oxidation by the highly reduced environment inside the cell.

The list of redox sensitive signal transduction pathways are steadily growing and current information suggests manipulation of the cell redox state may prove to be a strategy for the management of AIDS and some forms of cancer. The endogenous thioredoxin and glutathione system are of central importance in redox signaling and $\mathrm{N}$-acetyl L-cysteine (NAC) and alpha lipoicacid are known for clinical use in their efficacy to modulate cellular redox status.Lipoate captures the metabolic power of cell to continuously regenerate its reductive dithiol form.

\section{N-Acetyl l-Cysteine (NAC)}

NAC the preacetylysed form of simple amino acid cysteine, a synthetic precursor of cysteine and reduced glutathione has been in clinical use for more than 40 years. It is a powerful intracellular antioxidant, antitoxin improves immunity and is found naturally in foods.

\section{Structure}

NAC is a thiol compound which has a chemical formula C5H9NO3S and a molecular weight of 163.2 [7] NAC gets deacetylated to cysteine in the liver [8] In addition to increase in free and total NAC, additional increase in non-protein and protein SH groups, and small molecular weight protein bound thiols are found in the human plasma.
Both L-Cysteine and glutathione has been explored for their usage as supplements and NAC shows increased bioavailability. Glutathione has limited therapeutic usage as it is being rapidly hydrolysed by the intestines.

NAC may have a direct chelating effect on lead as seen by lowered serum lead levels. It prevents lead toxicity and reduces oxidative sequelae of lead exposure. NAC crosses cell membranes and is rapidly consumed in producing intracellular glutathione. By reducing extracellular cystine to cysteine, it acts as a source of $\mathrm{SH}$ groups and it can stimulate glutathione synthesis enhance glutathione- $\mathrm{S}$-transferase activity promote detoxification and act directly on reactive oxidant radicals [9].

NAC corrects the reduction in glutathione concentration and results in significant preservation of fluidity of membranes and of the activities of catalase, mitochondrial superoxide dismutase and different forms of glutathione peroxidase in biliary obstructed rats [10]. NAC is a powerful scavenger of hypochlorous acid and is capable of reducing hydroxyl radicals and hydrogen peroxide.SH groups are essential for defence against reactive oxygen species [11]. NAC can also prevent apoptosis caused by oxidative stress and promote cell survival by activating signal regulating pathways [12].

\section{NAC on oxidative damage in urolithiasis}

Hyperoxaluria is one of the major risk factors in human idiopathic calcium oxalate stone disease and its experimental induction was studied in rats. Exposure to oxalate has been shown to be toxic to renal epithelial cells with increased urinary excretion of marker enzymes [13]. Renal cell damage is associated with lipid peroxide production primarily caused by hyperoxaluria and the development of tissue injury is relative to its oxidant - antioxidant status of the cells [14]. Increased urinary calcium levels found in hyperoxaluric animals was controlled using methionine [15]. Phyllanthusniruri normalizes elevated urinary calcium levels found in stone formers [16] due to antioxidant action of NAC. Jonassen [17] proposed high concentrations of oxalate promotes stone formation in 2 ways 
1) By providing urinary conditions favorable to the formation of calcium oxalate crystal

2) By inducing renal injury that generates cellular debris and promotes crystal nucleation and attachment. NAC decreased urinary oxalate in hyperoxaluric animals which coincided with cysteine administration to ethylene glycol treated rats [18] with the decrease in urinary oxalate due to an adduct formation with cysteine and its conversion to oxalate. A similar mechanism may be proposed for NAC both being structural identities. Increased activities of urinary marker enzymes gamma glutamyl transferase, alkaline phosphatase, lactate dehydrogenase and pyrophosphatase were seen in hyperoxaluric rats indicative of cell injury $[19,20]$ mainly proximal tubular epithelium damage. Histologic changes in kidney tissue showed cellular injury in hyperoxaluria induced rats with bleb formation but NAC pretreated rats showed improvement. (Proceedings NHFR Conference2004)

\section{NAC on oxidative damage in diabetic rats}

NAC is a potent antioxidant due to its ability to stimulate reduced glutathione (GSH) synthesis therefore maintaining intracellular levels. NAC can be used as an antioxidant agent in alloxan- induced diabetic rats showing modulatory action on oxidative stress biomarkers [21].

Pubmed Therapeutic goods administration of Australia and Food Administration suggests NAC use in psychiatric disorders schizophrenia and bipolar disorder. Enhanced oxidative stress pathogenesis of several disorders like ischemic diseases of the heart, brain, neurogenerative disorders and cancer and also in human immunodeficiency virus (HIV) infection [22-26] as impaired antioxidant disturbance and particularly disturbed glutathione metabolism is seen in HIV patients [25-28]. Also impaired responsiveness and enhanced apoptosis may possibly involve increased intracellular hydroxyl radicals [10] tumor necrosis factor (TNF)-alpha related mechanisms [29,30]. Consumption of GSH is high during HIV infection and disease progression. GSH is known to play a major role in regulation of T-cell immune function. The clinical significance of the HIV associated glutathione disturbances is reflected as low thiol levels in both plasma [31] and CD4+ T cells [32] and is strongly associated with decreased survival of HIV infected patients. GSH depletion can enhance oxidative stress and also may increase excitotoxic molecules that can initiate cell death.GSH status is diminished in Lou Gehrig's disease (ALS)'Parkinson's and Alzheimer's disease. Hence can propose potential therapeutic approaches for preventing these diseases [33].

\section{References}

1. Meister (1974) Glutamine synthetase of mammals. In: The enzymes, 3rd ed., edited by P. Boyer, Academic press, New York 699-754.

2. Proceedings of the National Academy of Sciences (1970) Marian Orlowski and Alton Meister 67: 1248-1255.

3. Arias IM, Jakroby (1976) Glutathione Metabolism and function vol 6 Kroc Foundation series Raven press New York.

4. John M Gutteridge, Halliwell B (1993) Invited review: Free Radicals in Disease Processes: compilation of cause and consequence 19: 141-158.

5. Halliwell B (1999) Antioxidant defence mechanisms: from the beginning to the end (of the beginning). Free Radic Res 31: 261-272.

6. Hensley K, Robinson KA, Gabbita SP, Salsman S, Floyd RA (2000) Reactive oxygen species, cell signaling, and cell injury. Free Radic Biol Med 28: 14561462.

7. Ziment I (1988) Acetylcysteine: a drug that is much more than a mucokinetic. Biomed Pharmacother 42: 513-519.

8. Cotgreave IA, Berggren M, Jones TW, Dawson J, Moldéus P (1987) Gastrointestinal metabolism of $\mathrm{N}$-acetylcysteine in the rat, including an assay for sulfite in biological systems. Biopharm Drug Dispos 8: 377-386.
9. De Vries N, De Flora S (1993) N-acetyl-I-cysteine. J Cell Biochem Suppl 17F: 270-277.

10. Pastor A, Collado PS, Almar M, González-Gallego J (1997) Antioxidant enzyme status in biliary obstructed rats: effects of $\mathrm{N}$-acetylcysteine. J Hepatol 27: 363370.

11. Aruoma OI, Halliwell B, Hoey BM, Butler J (1989) The antioxidant action of $\mathrm{N}$-acetylcysteine: its reaction with hydrogen peroxide, hydroxyl radical, superoxide, and hypochlorous acid. Free Radic Biol Med 6: 593-597.

12. Zafarullah M, Li WQ, Sylvester J, Ahmad M (2003) Molecular mechanisms of $\mathrm{N}$-acetylcysteine actions. Cell Mol Life Sci 60: 6-20.

13. Khan SR (1997) Animal models of kidney stone formation: an analysis. World J Urol 15: 236-243.

14. Khan A, Wang W, Khan SR (2014) Calcium oxalate nephrolithiasis and expression of matrix GLA protein in the kidneys. World J Urol 32: 123-130.

15. Ravichandran V, Selvam R (1991) Increased plasma lipidperoxidation in vitamin B-6 deficient rats. Indian J Exp Biol 29: 56-58.

16. Nishiura JL, Campos AH, Boim MA, Heilberg IP, Schor N (2004) Phyllanthus niruri normalizes elevated urinary calcium levels in calcium stone forming (CSF) patients. Urol Res 32: 362-366.

17. Jonassen JA, Cao LC, Honeyman T, Scheid CR (2003) Mechanisms mediating oxalate-induced alterations in renal cell functions. Crit Rev Eukaryot Gene Expr 13: $55-72$.

18. Bais R, Rofe AM, Conyers RA (1991) The inhibition of metabolic oxalate production by sulfhydryl compounds. J Urol 145: 1302-1305.

19. Selvam R (2002) Calcium oxalate stone disease: role of lipid peroxidation and antioxidants. Urol Res 30: 35-47.

20. Khan SR, Shevock PN, Hackett RL (1992) Acute hyperoxaluria, renal injury and calcium oxalate urolithiasis. J Urol 147: 226-230.

21. Ribeiro G, Roehrs M, Bairros A, Moro A, Charão M, et al. (2011) N-acetylcysteine on oxidative damage in diabetic rats. Drug Chem Toxicol 34: 467-474.

22. Halliwell B (1999) Antioxidant defence mechanisms: from the beginning to the end (of the beginning). Free Radic Res 31: 261-272.

23. Hensley K, Robinson KA, Gabbita SP, Salsman S, Floyd RA (2000) Reactive oxygen species, cell signaling, and cell injury. Free Radic Biol Med 28: 14561462.

24. Aukrust P, Müller F (1999) Glutathione redox disturbances in human immunodeficiency virus infection: immunologic and therapeutic consequences. Nutrition 15: 165-167.

25. Dröge W, Eck HP, Mihm S (1994) Oxidant-antioxidant status in human immunodeficiency virus infection. Methods Enzymol 233: 594-601.

26. Aukrust P, Svardal AM, Muller F, Lunden B, Berge RK, et al. (1995) Increased levels of oxidized with glutathione in CD4+ lymphocytes associated with disturbed intracellular redox balance in human immunodeficiency virus type infection. Blood 86: 258-267.

27. Roederer M, Staal FJ, Osada H, Herzenberg LA, Herzenberg LA (1991) CD4 and CD8 T cells with high intracellular glutathione levels are selectively lost as the HIV infection progresses. Int Immunol 3: 933-937.

28. Eck HP, Gmünder H, Hartmann M, Petzoldt D, Daniel V, et al. (1989) Low concentrations of acid-soluble thiol (cysteine) in the blood plasma of HIV-1infected patients. Biol Chem Hoppe Seyler 370: 101-108.

29. Buttke TM, Sandstrom PA (1994) Oxidative stress as a mediator of apoptosis. Immunol Today 15: 7-10.

30. Dröge W, Eck HP, Mihm S (1992) HIV-induced cysteine deficiency and T-cel dysfunction--a rationale for treatment with $\mathrm{N}$-acetylcysteine. Immunol Today 13: $211-214$

31. Marmor M, Alcabes P, Titus S, Frenkel K, Krasinski K, et al. (1997) Low serum thiol levels predict shorter times-to-death among HIV-infected injecting drug users. AIDS 11: 1389-1393.

32. Herzenberg LA, De Rosa SC, Dubs JG, Roederer M, Anderson MT, et al. (1997) Glutathione deficiency is associated with impaired survival in HIV disease. Proc Natl Acad Sci U S A 94: 1967-1972.

33. Tözsér J (2001) HIV inhibitors: problems and reality. Ann N Y Acad Sci 946 $145-159$. 